\title{
Categories for Barriers to Digital Transformation in Higher Education: An Analysis Based on Literature
}

\author{
Bayu Rima Aditya, Ridi Ferdiana, and Sri Suning Kusumawardani
}

\begin{abstract}
For higher education institutions that encourage digital transformation, understanding the barriers are necessary for the digital transformation accomplishment. The purpose of this paper is to present a review of the literature on barriers to digital transformation in higher education. To get a wide overview in identifying the barriers to the implementation of digital transformation, a structured literature review was used to select the relevant studies published. Nine categories were identified based on the literature reviewed: vision, strategy and policy, resources, leadership, digital skill and knowledge, technology, adaptability, resistance to change, and government and economic. Our findings provided a fish-bone diagram that outlines twenty-two barriers to digital transformation in higher education. The main contribution of this study is a synthesis of the state of the art of barriers to digital transformation in higher education. We contribute to provide a common basic understanding of barriers to digital transformation in higher education to overcome barriers for improving the possibility of success. Moreover, we give an insight into future research on barriers exploration in the context of digital transformation in higher education.
\end{abstract}

Index Terms-Digital transformation, digital technology, digital innovation, higher education, policymakers, barriers framework.

\section{INTRODUCTION}

The trend of implementing digital transformation in the higher education sector began to be widely discussed in 2017 to respond to the effect of industrial revolution 4.0. At that time, a study was conducted on the total of 282 higher education institutions in developed and developing countries [1], [2], showing that the majority of their digital transformation journey was still in the initial stage, while others were already about one-third of the digital transformation implementation. However, the trend of digital transformation in 2020 increased, especially after the coronavirus broke out. During the COVID-19 pandemic, higher education institutions around the world were forced to use technology to support their teaching and learning process [3]. Based on this, it can be concluded that the higher education institutions in many countries have shown their awareness and understanding of the need for a digital transformation. By implementing digital transformation, the

Manuscript received April 14, 2021; revised June 23, 2021.

B. R. Aditya is with the Department of Electrical and Information Engineering, Gadjah Mada University, Indonesia. He is also with School of Applied Science, Telkom University, Indonesia (corresponding author; e-mail: bayu@tass.telkomuniversity.ac.id).

R. Ferdiana and S. S. Kusumawardani are with the Department of Electrical and Information Engineering, Gadjah Mada University, Indonesia (e-mail: ridi@ugm.ac.id, suning@ugm.ac.id). management of higher education institutions will be greatly helped to complete the higher education strategy by adding innovation to the system management and education program.

However, the digital transformation approach will be difficult to be successfully implemented in higher education institutions that are not familiar with change and innovation. This is because educational institutions at least must go through two crucial processes in implementing digital transformation: 1) the change process towards new education environment [4]-[6], and 2) the process of technology adoption and integration to the education system [7], [8]. In other words, implementing digital transformation in higher education is not an easy matter. There are still many barriers to the implementation of digital transformation in the higher education sector.

The basic problem that underlies this study was about what barriers need to be considered when implementing digital transformation in higher education. Even though several barriers to digital transformation in higher education had been identified by previous literature [1], [9], [10], there was no concept in those studies developed to compile the description and list of the barriers completely. Therefore, in practice, the use of definition and description of the barriers to digital transformation in higher education sector becomes unclear. With that in mind, as the ground necessity, which is also the problem that must be solved by this research, it is important to have a comprehensive common understanding about what types of barriers can be found when implementing the digital transformation program in the higher education sector. Therefore, it is important to formulate and define the barriers systematically and thoroughly in the context of digital transformation in the higher education sector [11].

\section{METHOD}

To get a wide overview in identifying the barriers to the implementation of digital transformation, a structured literature review adopted by Petersen et al. [12] was used to select the relevant studies published. Based on Fig. 1, we followed five main steps to carry out a mapping process: 1) we determined the research question, 2) we determined search terms, 3) we filtered the literature, 4) we excluded the criteria, and 5) we synthesized the relevant literature.

In the first step, we defined a research question. The basic problem that underlies this study was about what barriers could affect the implementation of digital transformation in higher education. To answer the question, in the second step, we used a combination of "digital transformation", "higher 
education", "digital readiness", "digital technology", and "e-learning" as search terms and queries. As sources selection and databases, we used IEEE, Elsevier, Springer, Science Direct, and ERIC to find the academic literature published in 2012-2021. In steps three and four, to find relevant literature, according to titles, abstracts, and full text, we selected literature with the following criteria: 1) the literature discussed the organizational change, and 2) literature discussed the IT adoption and integration. Additionally, only articles were written in English were chosen. A total of 21 relevant pieces of literature covering qualitative and quantitative studies of various countries and types of higher education were selected for the analysis process. In the final step, thematic coding [13] was used to identify barriers. In addition, we used a fishbone diagram to categorize the resulted review. In this study, barriers can be interpreted as a challenge, a risk, a trouble, an obstacle, or a limitation that prevents higher education to achieve success in the digital transformation process [14].

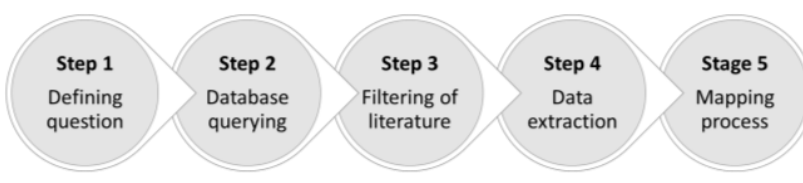

Fig. 1. The five main steps of the methodology.

\section{RESULTS}

The present study identified 22 barriers to be effective digital transformation in the context of higher education based on a literature review on issues with the digital transformation in higher education. The result of the identification of barriers can be seen in Fig. 2.

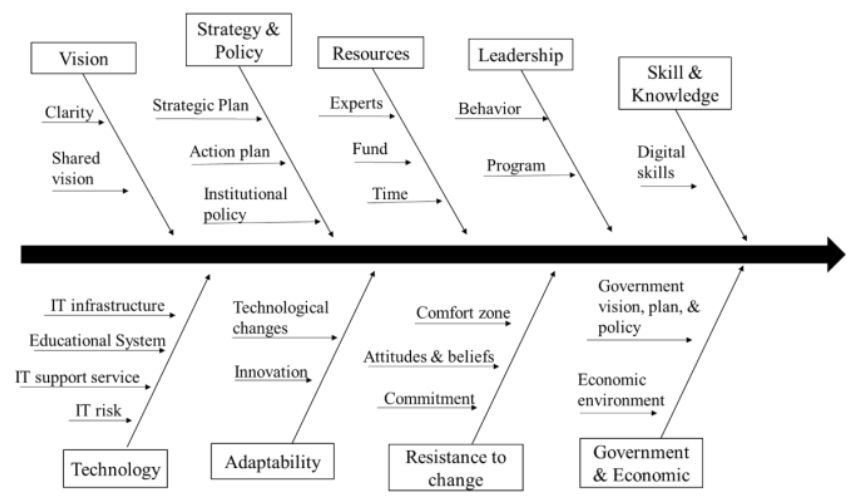

Fig. 2. The fishbone diagram of barriers to digital transformation in higher education

\section{A. Vision}

\section{1) Clarity vision}

A study by Mark et al. [10] found that most higher education institutions did not have a holistic vision of digital transformation yet. In addition, they lack the support and skill to form and deciding the most suitable new vision to achieve the success of the implementation of digital transformation is a barrier to the higher education institution [15], [16]. Thus, what should be the goal of the digital transformation becomes unclear.

\section{2) Shared vision}

A study by Khan et al. [16] indicated that a vision of digital transformation allows higher education institutions to start, direct, and reach the desired goal. According to [8], all academic communities tend to have different perspectives in understanding a vision. The difference of department in which they worked is the background factor of this difference in understanding. The importance of a common vision is also shown by Butler et al. [15] who stated that the impact of the misalignment of the vision is a lack of involvement to invest in the growth of the digital transformation.

\section{B. Institutional Strategy and Policy}

\section{1) Strategic plan}

A study by Kaminskyi et al. [17] showed that the implementation of digital transformation in higher education surely needs a new strategy. Unfortunately, the lack of strategy related to the process of digital transformation still could be found in most higher education institutions, including from the organizational strategy [18] to the technical strategy to support the process of teaching and learning [16], [19], [20].

\section{2) Action plan}

A study by Kaminskyi et al. [17] found that higher educations are restricted in the planning about how to start the digital transformation, either it is related to the plan of education service transformation and the teaching itself or the plan of the transformation process of the current business. Meanwhile, as stated by Khan et al. [16] and Rafiq et al. [21], the most crucial steps in realizing a vision and new objective are by translating the strategy into a clear and concrete action plan, in this case, the planning with a non-complicated process, yet not too simple, having a reasonable volume, and ensuring the time and effort required.

\section{3) Institutional policy}

As stated by Gregory and Lodge [22], the lack of clarity from the institution management about the goal of the digital transformation showed that the management does not have any clear idea on how to execute the digital transformation [22], and not express the sincerity to implement it in the institution [23]. Several kinds of research have specifically recorded several findings regarding the lack of institutional support for the digital transformation program, in this case, are the policy of academic staff workload [22], the policy of the development of the digital academic ecosystem [15], and the policy of institution capability development to support the technological innovation in the process of teaching and learning [24]. Therefore, policy support from the senior executive is necessary to create the clarity of technology innovation in the process of digital transformation [25].

\section{Resources}

\section{1) Experts}

A higher education institution is still lacking human resources to support the success of the digital transformation. The previous study that was conducted by Kalolo [26] on several higher education institutions in developing countries showed that the lack of human resources became the main problem in the higher education institution that will implement the digital transformation, especially in the effort 
to move and integrate the digital technology in teaching-learning activities. The study is in line with what has been shown by Marks et al. [10], Schaffhauser [19], and Rafiq et al. [21] who also confirmed that the availability of resources with technical skills in the innovation of the education system is scarce.

\section{2) Funds}

The implementation of the digital transformation needs a great sum of the fund. However, the internal funding resource still becomes a problem in the process of implementing digital transformation. A study by Watty et al. [25] shown that several accounting faculties in Australia recorded how lack of funds, in most times, prevents the will and skill of the teaching staffs to introduce new technology to their class. Also, a study by Rafiq et al. [21] shown that the internal funding resource that is available for the development process and innovation is limited.

\section{3) Institutional policy}

The lack of time still becomes one of the biggest problems in the process of digital transformation in higher education. The study that was conducted by Khan et al. [16], Schaffhauser [19], and Watty et al. [25] stated that the academic staff was overwhelmed with the heavy workload related to the research, teaching, and other administrative conditions. Consequently, it made them had very little time to be involved in the new technologies.

\section{Leadership}

\section{1) Leadership behavior}

Ineffective leadership is still the main problem and directly gives impacts the ineffectiveness of digital transformation. A higher education institution needs to develop its strategies to be able to respond to the culture change and leadership behavior change as the effect of the digital transformation process [17].

\section{2) Programs}

A study by Kerroum et al. [18] showed that one of the causes of the slow process of digital transformation is the lack of skills of the institution leaders to governance the digital transformation programs. The executive team has not been aware that digital transformation needs a lot of work to be able to achieve its success.

\section{E. Digital Skills and Knowledge}

The digital transformation has changed the learning activities and at the same time, many tools can be used by a higher education to support the teaching-learning activities. Integrating digital technology into the educational system needs new skills, knowledge, and even attitude related to digital technology in education [16]. However, the lack of digital competence such as the skill, competitiveness, and knowledge to develop and decide which technology appropriate with the teaching-learning activity, still becomes the main obstacle in various higher education institutions [16], [26]-[30]. As presented in the research by Watty et al. [25], the academic staffs who are not used to and lack understanding of digital technology were unable to execute the ICT integration into their program and learning environment, even though the success of the innovation in the education sector highly depends on the skill and knowledge of either the teaching staff or even their students [16]. Consequently, many education institutions do not understand how technology can improve the teaching-learning activity so that it inhibits the use of ICT in their teaching-learning process [17], [20], [21].

\section{F. Technology}

\section{1) IT infrastructure}

The digital transformation will be not successful enough if higher education is not able to provide adequate technical support in implementing the digital transformation. Several types of research have reported that the lack of infrastructure development in many higher education institutions have burdened the use of digital technology, such as Wi-Fi, terrible internet access, and slow connection speed [16], [18], [19], [21], [23], [31], even though the research by Kaminskyi et al. [17] has concluded that the IT architecture of the higher education institution is the basis of the digital transformation of the whole system digitalization process. A high-speed internet connection is one of the pre-conditions to integrate ICT into the teaching-learning system. Equivalently, Limaj and Bilali [23] declared that the role of the internet is very important to enable students and lecturers to access education at any time and from anywhere, for example, to use it for video conference, online learning, live presentation tools, and video courses. Besides, the research result obtained by Khan et al. [16], Schaffhauser [19], and Looi et al. [29] reported that resources such as a computer, laptop, printer, multimedia projector, scanner, and tablet cannot be fully available in many higher education institutions.

\section{2) Educational systems}

Digital technology integration in the teaching-learning process is a complex negotiation process among many decision-makers in higher education institutions [15]. A study by Marks et al. [10] stated that the newest digital technology does not guarantee compatibility with the existing systems. By that point, higher education will face obstacles and be forced to put more attention on data structure and processing or custom integration. Another problem was also presented by Lillejord et al. [32] is that it seems the academics did not use a scientific approach when integrating digital technology into their class activities.

\section{3) IT support service}

The digital transformation in higher education involves new technology in its process. As a consequence, an appropriate mechanism of technical support must be available to give more trust and ability to the teaching staffs in creating and using digital technology in their teaching-learning activities, including real-time virtual support to help them solve many questions and daily technical disturbances that were found by Schaffhauser [19], Shelton [24], and Watty et al. [25]. A study by Watty et al. [25] confirmed that as an effect of no technical support, many faculties refuse to adopt digital technology in their teaching-learning process. The report is in line with the founding of [20] that also shows that higher education institutions do rarely invest in the service design when they try to do a digital initiation. They tend to be more focused on 
security which is often related to comfort. Besides, from the students' perspectives, the technical support must make them possible to focus on their study content, give support for the organizational study problem, and give easy access to resources, such as literature and other software [20].

\section{4) IT risk}

The increase of the IT risk in the process of digital transformation in higher education is real and cannot be ignored. Likewise, issues such as data quality and information are also being discussed by Limaj and Bilali [23] The teaching staff and students must be careful to always check and verify the data and information inside their academic platform.

\section{G. Adaptability}

\section{1) Technological changes}

A study by Khan et al. [16] showed that several teaching staffs do not desire to try to use the technology in their class, even there are teaching staffs that do not want to use technology at all. The lack of interest and motivation to develop and input the technology into the education system still become an obstacle in the digital transformation process. The result of the research by Sinclair and Aho [30] also is recorded that the obstacles such as fear of technology and worries of the negative effect of technology adoption still widely exist among the lecturers. This result was also emphasized by Watty et al. [25] who stated that for some people, technological adoption can be fun and comfortable, but several others are not experiencing the same feelings. Therefore, it makes them scared of failure and reluctant to study the new skills and process.

\section{2) Innovation}

Digital transformation requires extra responsibility to adopt digital technology into the academic system. Using up-to-date hardware and software resources is the main feature of technology innovation. Yet, the experience is poor in a higher education [16], [22], [33], [34]. It is different when compared with companies, higher education institution is an organization that focuses on education and historically does not have experience in innovation [15]. The research that was conducted by Looi et al. [29] stated that every teacher has differences in readiness and experiences related to technology, and in practice, they are not confident enough and also nervous when being involved in a digital room. The research that was conducted by Thoring et al. [20] showed that even though the new student registration in many higher education institutions has been implemented online, the important aspect related to the study activity itself is still not conducted digitally. As stated by Stüber [8] and Donnelly [35], the lecturers still limit and refrain from any extra effort to conduct innovative teaching. The result of the research by Watty et al. [25] also confirmed that there were many teaching staffs not interested in innovation through technology. It is related to the lack of personal interest among teaching staffs in transforming their teaching approach, including the use of IT.

\section{H. Resistance to Change}

1) Comfort zone
People tend to do something in a particular way and reluctant to leave their comfort zone [32]. As stated by Gregory and Lodge [22], creating an academic culture is a difficult process and takes a long period. With the shifting of the teaching methodology in higher education to implement technology into the teaching practice, add with the change on a new institution corporation style, the identity change will not be only at the academic level, but also in all levels [22], [36]. As stated by Gregory and Lodge [22], the characteristic of academic identity which is flexible and sometimes varies can be an obstacle and a trigger of the culture change. In the research that was conducted by Thoring et al. [20], it was reported that there were still many teaching staffs that were not progressive toward the occurring change, and also tended to not willing to change their current situation [20]. They prefer to read printed readings instead of digital copies, even there are still teaching staff that still have difficulties digitalizing all their notes and writings. Several lecturers also still hold the strong principle of the best practice that has been proven to achieve their goal with technological knowledge that they own. The research of Stüber [8] also showed a similar condition that reported that there are still many lecturers that feel not necessary to change and even they try to avoid the use of a particular digital technology. The lack of experience and confidence is the cause of those avoidances.

\section{2) Attitudes and beliefs}

The digital transformation of higher education connects not only the technology but also the pedagogy aspect and teaching conception [30]. Therefore, the success of the use of the digital technology application in study activities highly depends on the attitude and trust of the lecturer [16]. The lecturer needs to be involved in the transformation of the concepts related to the learning concept, student role, and also their role as a lecturer. In the research that was conducted by Sinclair and Aho [30], it was reported that obstacles such as technological dear and worries of the negative effect of the adoption of ICT are still found among most teaching staffs. This study is supported by the result of the research by Khan et al. [16] that stated the lecturers who are technologically incapable but have a positive mindset towards the ICT will need less effort to learn the skills that are necessary to implement ICT in the class activity. Therefore, changing the negative attitude of each individual is very important to improve their ICT skills. This matter must be overcome and understood by the lecturers that the existence of technology is not a barrier [32]. If the lecturers want to succeed in using the technology in their class, they have to have a positive attitude toward the use of technology.

\section{3) Commitment}

The lecturer's characteristic in commitment towards the use of technology will affect the students' attitude and the choice over the use of the technology [23], [28]. However, a commitment to invest in the use of digital technology in the teaching-learning process still becomes a problem in the process of digital transformation in higher education. As shown by Limaj and Bilali [23], a large number of teaching staffs tend to exclude digital technology, still use a traditional teaching style, and apply old-time communication patterns to their students. 


\section{Government Support and Economic}

\section{1) Government vision, plan, and policy}

A study by Khan et al. [16] showed that several teaching staffs did not desire to try to use the technology in their class, even there were teaching staffs that did not want to use technology at all. The lack of interest and motivation to develop and input the technology into the education system still became an obstacle in the digital transformation process. The result of the research by Sinclair and Aho [30] also recorded that the obstacles such as fear of technology and worries of the negative effect of technology adoption still widely exist among the lecturers. This result was also emphasized by Watty et al. [25] who stated that for some people, technological adoption can be fun and comfortable, but several others are not experiencing the same feelings. Therefore, it makes them scared of failure and reluctant to study the new skills and process.

\section{2) Economic environment}

A study by Chipembele and Bwalya [31] stated that the condition of an economic environment that is not supportive can inhibit the success of the whole integration and the use of ICT itself. Hence, it is urgent to be aware of the economic environment to support the success of the whole digital transformation process in the higher education sector.

\section{DISCUSSION}

\section{A. Knowledge Contributions}

The results show that higher education institutions are faced with a long process towards the successful implementation of digital transformation. Based on the framework, a short synthesis of the state of the art of barriers to digital transformation in higher education can be summarized in 4 pillars. First, there are four key factors related to a social pillar. The first is leadership. The characteristics of higher education that are highly dependent on leadership cause the success of digital transformation to depend heavily on leadership [2]. The second is digital technology skills and knowledge. The integration of digital technology into the education system has transformed academic activity. However, this digital technology will only waste time, effort, and money if the lecturers, staff, and students cannot use it [37]. The third is adaptability. Digital transformation certainly provides additional responsibilities for adopting digital technology into the academic system [34]. It is important to increase the awareness and better understanding by conducting a seminar, workshop, and other things that must be performed properly to educate the benefit of the changes. The fourth is the resistance to change. This classic problem will always exist. So far, those who feel comfortable will find it difficult to accept new changes. Higher education must quickly respond to this innovative change that will change almost all aspects of higher education [38].

Second, there are four key factors related to a technological pillar. The first is the IT infrastructure. The digital transformation in higher education can be less successful if it is unable to provide adequate technical support. Policymakers must understand more concretely the interdependence between infrastructure, curriculum, and learning processes in the digital ecosystem [39]. The introduction of ICT into the system, of course will have an impact on many other aspects outside the system [40]. The second is IT risk. The use of various new technologies in the academic system means the emergence of new and increasingly complex risks. Ensuring security, privacy, and compliance is the key to enable higher education institutions to perform digital transformation with confidence [1]. The third is the embedding of ICT into the system. The old systems that have existed in higher education are usually developed and operate in a decentralized manner. Thus, many services are not interconnected. The fourth is the IT support service. IT services should be aimed at giving students, teachers, and administrative staff greater confidence and abilities in creating and using digital technology for learning [31].

Third, there are three key factors related to organizational perspective. The first is the vision. Besides the need for clarity on the vision of digital transformation, the importance of communicating the vision to all levels in higher education institutions needs to be emphasized. Many studies state that employees' unpreparedness for a change is influenced by the ineffectiveness of the message of change being communicated [41]. The second is the institutional plan and policy. A key factor that is no less important is the support from management. To remain relevant to the goals of digital transformation, higher education needs to build institutional policy, so that lecturers, staff, and related stakeholders can feel more real in being involved [9]. The third is the resources. Limited resources are also still a challenge for higher education institutions, starting from the limited number of experienced experts in the digital transformation, limited funds, to limited time.

Finally, there are two key factors related to a governmental pillar. Policy direction and support from the government, as well as economic conditions, are also important in supporting the realization of digital transformation in higher education.

\section{B. Implications for Practice}

This identified barriers category is the initial step to standardize the description of barriers. Before higher education institutions can implement a digital transformation, policymakers need more understanding of barriers, and the strategies should be adapted. Identifying and managing the barriers have an important role in successful digital transformation. It means that by integrating this barrier into existing strategies and policies, the point of view of the barriers will be handled properly and better compatibility can be achieved. When we analyze our findings based on the previous literature, we can say that the barriers identified for various contexts of digital transformation in the higher education sector are different. As an example, the critical barriers to digital transformation in higher education institutions In Bangladesh [16] are different from United Arab Emirates (UAE) higher education institutions [10], as well as different from Indonesian higher education institutions [42]. A more investigation of the barriers looks important to find managerial and technical solutions for 
overcoming the barriers in each context of digital transformation in higher education. Some benefits that might be used in practice include: 1) analyzing which barriers are most likely to occur in a specific context more specifically, 2) analyzing whether the use of strategies and policies can break down barriers, 3) analyzing barriers in digital transformation processes in general, and 4) analyze whether it is feasible to design and develop new strategies for digital transformation.

\section{Limitation and Future Works}

This study is limited as an early review of the barriers to digital transformation in higher education based on a review of literature, so further empirical studies are needed to control the validation of these initial sets of barriers. Also, these barriers only described the barriers generically, it needs to be specified into certain sub-contexts. However, it can already be used as a base to intensify research related to digital transformation barriers in the higher education sector and to stimulate the potential for further research. This study will make it possible to conduct further research, such as the adaptation of the barrier framework to certain sub-contexts, and comparison of barriers in the different types of higher education. The results of this study also make it possible to focus on mapping possible intervention solutions. Identifying and overcoming all barriers does require in-depth consultation and discussion with stakeholder groups related to higher education institutions. Then the emergence of barriers can be overcome.

\section{CONCLUSION}

For higher education institutions that encourage digital transformation, understanding the barriers are necessary for the digital transformation accomplishment. Without a good knowledge of barriers, the policymakers are difficult to design the right goals for the implementation of digital transformation. This research has presented the nine categories which outline twenty-two barriers to digital transformation in the higher education sector. Overall, the results of the categorization of the barriers will provide policymakers with a better understanding of the barriers and give new insights on how to implement digital transformation effectively. The implementation of digital transformation is a complex topic and seems to be a little-studied in the context of higher education.

This paper presents a basic understanding of higher education to overcome barriers for improving the possibility of the success of the digital transformation. Other than that, by keeping in mind the limited number of research projects about the barriers to digital transformation in higher education, this research gives a contribution in acting as a base for further research projects in the effort to overcome the impact of each barrier on the implementation of digital transformation in the higher education sector. Aside from it, this research systematically presents new concepts that formulate various barriers from many literatures.

The main contribution of this study is an artifact. In this context, this research contributed to the field by providing a synthesis of the state of the art of barriers in the implementation of digital transformation in higher education through a systematic literature review. It is important to emphasize the need for research with a focus on a better description of the context of higher education to support the analysis of the barriers in theoretical models. Also, considering that the barrier concept in this study is the first in the topic of digital transformation in higher education, the initial classification results in the form of a set of barriers certainly have the potential to carry out further investigations and development of intervention solutions to facilitate the realization of the digital transformation program in the higher education sector.

\section{CONFLICT OF INTEREST}

The authors declare that they have no competing interest.

\section{AUTHOR CONTRIBUTIONS}

This research is part of dissertation research conducted by the first author and other authors as promotor and co-promotor. All authors read and approved the final manuscript.

\section{REFERENCES}

[1] Microsoft. (2017). 87\% of education leaders believe they need to be a digital institution to succeed. [Online]. Available: https://news.microsoft.com/apac/2017/11/16/87-education-leaders-bel ieve-need-digital-institution-succeed/

[2] N. Ventures. Digital transformation in higher education 2017. [Online]. Available:

https://www.navitasventures.com/wp-content/uploads/2017/08/HE-Di gital-Transformation-_Navitas_Ventures_-EN.pdf

[3] IESALC-UNESCO. (2020). COVID-19 and higher education: Today and tomorrow: Impact analysis, policy responses and recommendations. [Online]. Available: http://www.iesalc.unesco.org/en/wp-content/uploads/2020/04/COVID -19-EN-090420-2.pdf

[4] C. Haythornthwaite and R. Andrews, E-Learning Theory and Practice, Sage Publications Ltd 1st edition, 2011.

[5] P. Kähkipuro. "Case Aalto University - Digital transformation in Higher Education," Science and Technology, vol. 7, pp. 81-88, 2015.

[6] A. Tubaishat and A. Lansari, "Are students ready to adopt e-learning? A preliminary e-readiness study of a university in the Gulf Region," International Journal of Information and Communication Technology Research, vol. 1, no. 5, pp. 210-215, 2011.

[7] V. Đurek, N. B. Ređep, and B. Divjak, "Digital maturity framework for Higher Education institutions," Central European Conference on Information and Intelligent Systems, 2017.

[8] J. Stüber, "Barriers of digital technologies in higher education: A teachers' perspective from a swedish university", Master thesis in Linnaeus University, 2018.

[9] A. Gronberg. (2017). Digital transformation in higher education. [Online]. Available: https://www.hoonuit.com/blog/digital-transformation-in-higher-educa tion

[10] A. Marks, M. AL-Ali, R. Attasi, A. A. Elkishk, and Y. Rezgui, "Digital transformation in higher education: Maturity and challenges post COVID-19," Advances in Intelligent Systems and Computing, vol. 1330, 2021.

[11] P. Reid, "Categories for barriers to adoption of instructional technologies," Education and Information Technology, vol. 19, pp 383-407, 2014.

[12] K. Petersen et al., "Systematic mapping studies in software engineering," presented at $12^{\text {th }}$ International Conference on Evaluation and Assessment in Software Engineering (EASE): University of Bari, Italy, 2008.

[13] R. Boyatzis, Transforming Qualitative Information: Thematic Analysis and Code Development, Thousand Oaks, CA: SAGE, 1998.

[14] H. Pirkkalainen and J. M. Pawlowski, "Global social knowledge management-understanding barriers for global workers utilizing social software," Computers in Human Behavior, vol. 30, pp. 637-647, 2014. 
[15] D. Butler, M. Leahy, P. Twining, et al., "Education systems in the digital age: the need for alignment," Technology, Knowledge and Learning, vol. 23, no. 473, 2018.

[16] S. H. Khan, M. Hasan, and C. K. Clement, "Barriers to the introduction of ICT into education in developing countries: The example of Bangladesh," International Journal of Instruction, vol. 5, no. 2, pp. 61-80, 2012.

[17] O. Y. Kaminskyi, Y. O. Yereshko, and S. O. Kyrychenko, "Digital transformation of university education in Ukraine: Trajectories of development in the conditions of new technological and economic order," Information Technologies and Learning Tools, vol. 64, no. 2, pp. 128-137, 2018.

[18] K. Kerroum, A. Khiat, A. Bahnasse, E. Aola, and Y. Khiat, "The proposal of an agile model for the digital transformation of the University Hasan II of Casablance 4.0," Procedia Computer Scence, vol. 175, no. 2020, pp. 403-410, 2020.

[19] D. Schaffhauser, "Biggest barriers to digital learning: lack of time, lack of devices," The Journal and Campus Technology, 2017.

[20] A. Thoring, D. Rudolph, and R. Vogl, "Digitalization of Higher Education from a student's point of view," European Journal of Higher Education IT, 2017.

[21] M. Rafiq, S. H. Batool, A. F. Ali, and M. Ullah, "University libraries response to COVID-19 pandemic: A developing country perspective,' The Journal of Academic Librarianships, vol. 47, no. 2021, 2021.

[22] M. Gregory and J. Lodge, "Academic workload: the silent barrier to the implementation of technology-enhanced learning strategies in higher education," Distance Education, vol. 36, no. 2, pp. 201-230, 2015.

[23] E. Limaj and E. Bilali, "Examining digital technology constraints on Higher Education in developing countries through the lens of the capability approach," presented at the 22nd Pacific Asia Conference on Information System, 2018

[24] C. Shelton, "Giving up technology and social media: Why university lecturers stop using technology in teaching," Technology, Pedagogy and Education, vol. 26, no. 3, pp. 303-321, 2017.

[25] K. Watty, J. McKay, and L. Ngo, "Innovators or inhibitors? Accounting faculty resistance to new educational technologies in higher education," Journal of Accounting Education, vol. 36, pp. 1-15, 2016.

[26] J. F. Kalolo, "Digital revolution and its impact on education systems in developing countries," Education and Information Technologies, 2019.

[27] M. Bond, V. I. Marín, C. Dolch, et al., "Digital transformation in German higher education: student and teacher perceptions and usage of digital media," International Journal of Education Technology in Higher Education, vol. 15, no. 48, 2018.

[28] H. J. Kim, A. J. Hong, and H. Song, "The roles of academic engagement and digital readiness in students' achievements in university e-learning environments," International Journal of Education Technology in Higher Education, vol. 16, no. 21, 2019.

[29] C. K. Looi, S. W. Chan, and L. Wu, "Crisis and opportunity: Transforming teachers from curriculum deliverers to designers of learning," Radical Solutions for Education in a Crisis Context. Lecture Notes in Educational Technology, Springer, Singapore, 2021.

[30] J. Sinclair and A. M. Aho, "Experts on super innovators: understanding staff adoption of learning management systems," Higher Education Research and Development, vol. 37, no. 1, pp. 1-15, 2018

[31] M. Chipembele and K. J. Bwalya, "Assessing e-readiness of the Copperbelt University, Zambia: Case study," International Journal of Information and Learning Technology, vol. 33, no. 5, pp. 315-332, 2016.

[32] S. Lillejord, K. Børte, K. Nesje, and E. Ruud, "Learning and teaching with technology in higher education - A systematic review," Osle: Knowledge Centre for Education, 2018.

[33] L. Mishra, T. Gupta, and A. Shree, "Online teaching-learning in higher education during lockdown period of COVID-19 pandemic," International Journal of Educational Research Open, vol. 1, 2020.

[34] A. O. U. Onuka, "African higher education transformation for quality outcome," Sustainable Transformation in African Higher Education, pp. 3-24, SensePublishers, Rotterdam, 2017.

[35] R. Donnelly, "Blended problem-based learning in Higher Education: the intersection of social learning and technology," Psychosociological Issues in Human Resource Management, vol. 5, no. 2, pp. 25-50, 2017.
[36] A. B. Scholkmann, "Resistance to (digital) change: Individual, systemic and learning- related perspectives," Digital Transformation of Learning Organizations, chapter 13, pp. 219-236, 2021.

[37] M. Chauca, Y. Phun, O. Curro, C. Chauca, R. Yallico, and V. Quispe, "Disruptive innovation in active activity-based learning methodologies through digital transformation," International Journal of Information and Education Technology, vol. 11, no. 4, pp. 200-204, 2021.

[38] M. A. M. Khairi, I. Faridah, H. Norsiah, and M. A. A. Zaki, "Preliminary study on readiness to teach online due to Covid-19 pandemic among university academician in Malaysia," International Journal of Information and Education Technology, vol. 11, no. 5, pp. 212-219, 2021

[39] T. Karvonen, H. Sharp, and L. Barroca, "Enterprise agility: Why is transformation so hard?" Lecture Notes in Business Information Processing, vol. 314, 2018

[40] S. Narayan, Agile IT Organization Design: For Digital Transformation and Continuous Delivery, Addison-Wesley Professional, 2015.

[41] J. Allen, N. L. Jimmieson, P. Bordia, and B. E. Irmer, "Uncertainty during organizational change: Managing perceptions through communication," Journal of Change Management, vol. 7, no. 2, pp. 187-210, 2007.

[42] B. R. Aditya, R. Ferdiana, and S. S. Kusumawardani, "Identifying and prioritizing barriers to digital transformation in higher education: A case study in Indonesia," International Journal of Innovation Science, 2021.

Copyright $\odot 2021$ by the authors. This is an open access article distributed under the Creative Commons Attribution License which permits unrestricted use, distribution, and reproduction in any medium, provided the original work is properly cited (CC BY 4.0).

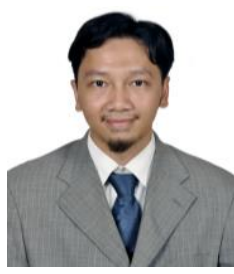

Bayu Rima Aditya is a Ph.D student in the Department of Electrical and Information Engineering, Gadjah Mada University, Indonesia. He is a member of the Applied Information Systems Research Group of the Applied Science Faculty and Lecturer at Telkom University, Indonesia. His main research interests include e-learning, modern IT audit, and information system.

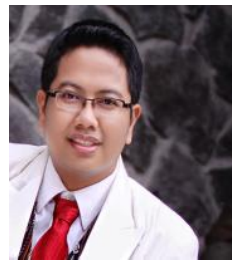

Ridi Ferdiana is an associate professor at Gadjah Mada University in the Department of Electrical and Information Engineering, Indonesia. He works in the Department of Electrical and Information Engineering. He holds several certifications. Having Microsoft Certified Technology Specialist in Windows Technology, ASP.NET, and Distributed Development, Microsoft Certified Professional Developer for Enterprise Solution. Microsoft Certified IT Professional for SQL Server Development, Microsoft Technology Associate for software development and software testing, Microsoft Office Specialist Expert for Office 365 and 2019, Microsoft Certified Solution Expert for SharePoint and Messaging, AWS cloud practitioners, AWS solution architect associate, AWS Accredited educator, Azure Certified in Data, Fundamental, and an active Microsoft Certified Trainer since 2009. His main scope of interest is focused on computer and human interaction, software engineering methodology, and video game technology.

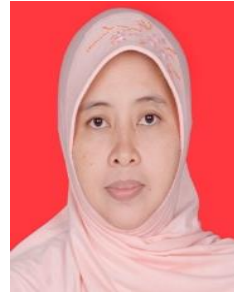

Sri Suning Kusumawardani is an associate professor of electrical and information engineering at Gadjah Mada University, Indonesia. She works in the center for academic innovation and studies at Gadjah Mada University. She has been engaged in a number of various education projects involving e-learning and digital transformation. Her research interes involves expert systems, knowledge management, knowledge representation, e-learning, and the

semantic web 